\title{
Indifference, Apathy, and Preparedness
}

\author{
Marvin L. Birnbaum, MD, PhD
}

The whole frame of things preaches indifferency.

Emerson,

Essays, First Series: Experience

A keynote of this issue is the four papers that pertain to the functioning of hospitals and the personnel that staff them during a disaster or mass-casualty incident. These papers include: 1) a comprehensive review of the problems encountered by hospitals during disasters and mass-casualty incidents (Milsten); 2) definition of the patient population encountered by a communitylevel hospital following an earthquake in a densely populated area (Kazzi); 3) an analysis of disaster plans for the emergency departments of four public hospitals (Lee et al); and 4) a reminder of the additional stresses placed upon health professionals during a disaster that must be considered in the mobilization of medical personnel (Nocera). Each highlights a different, but important aspect of what happens or could happen to a hospital during a disaster or mass-casualty situation. One obvious conclusion that can be drawn from these papers is that hospitals and their staffs are vulnerable to both disasters and the events that precipitate them.

These papers provoked me to examine all of the past papers published in Prehospital and Disaster Medicine that have dealt with hospitals during disasters. A bibliography of what has been published is provided at the end of this discussion. I am surprised by the relative paucity of research about hospitals and their staff that has appeared in PDM, scarcely only a dozen in 10 years. Furthermore, of the more than 100 excellent references provided by Milsten in the current issue, less than $30 \%$ directly deal with the impact of disasters on hospitals. However, combined, these references address many of the issues that our institutions may face and provide some tools for enhancing our abilities to deal with disasters.

One of the inferences from the Milsten analysis is that regardless of the event that precipitates the disaster, many of the failures experienced by hospitals are common and the information provided should be integrated into the disaster plans for our respective hospitals. This observation should provoke us to examine the state of preparedness for our respective hospitals. But, how many of us have done this? And furthermore, even if we have made such an assessment, with few exceptions, it is not likely that such findings would provoke a positive response by either the administration or the staff of the hospital.

Moreover, we cannot look to others to initiate change. It seems clear from the data presented in the papers provided in this issue and in the many other references, that even when detailed and potentially helpful plans for the conduct of a hospital and its staff during periods of overwhelming casualties have been developed, very few of the medical and nursing staff are well-versed or even acquainted with such plans. It seems that knowledge of such plans is of little interest to our colleagues, or at least they have more important things to do with their time. Even when mandatory exercises are conducted, they are viewed either as an imposition or as a joke. They are conducted only to place a check mark in a box to show that such an exercise has occurred.

Of course, such exercises and drills are play-acting at its best and worst. However, in hospitals that have had the unfortunate experience as to have been involved in a real disaster, such exercises are taken seriously. Once you have been burned by the reality of what happens, you do not forget. You are plagued by the memory of your time of testing and your feelings of inadequacy during such a period. Unless they have been involved directly, they tend to take the attitude that it is so unlikely to occur here, that they have better things to do with their time and had best invest their limited resources into areas that more likely will produce a return for their investment. I dare say that this latter attitude has been present in all of us until we became directly involved. When it does happen..., then we implore, "If only we had....!" I wonder what the cost of such apathy has been? How should we measure the impact of our indifference?

Those of us who read and think about disasters and their impact on the health-care personnel and facilities responsible for the provision of medical care during such stressful times, will be stimulated and concerned once again as we read the materials provided in this issue. We have tried to get others to understand what it is like. But, it doesn't seem to impact on those not regularly involved. Each of us has experienced the frustration when our pleas have been turned aside or taken lightly. How can we get others to listen to our message, learn from our experiences, sense our terror, and appreciate our feelings of inadequacy? There is little worse in our professional life than the feelings of inadequacy we have experienced when we have not been prepared. Each of us has experienced these feelings at some point when time was of essence and we did not know how to operate a defibrillator or other device. How can we stimulate enough interest to get some resources applied to preparedness and training? How can we co-opt our col- 
leagues into our mind set? Disaster Medicine in areas in which our colleagues believe there is little likelihood of such an event occurring is a lonely profession.

An interesting process is underway in parts of the United States. Suddenly, the government has become concerned about terrorism. Suddenly, a substantive resource pool has become available. Many courses of training and exercises are being conducted. But, I wonder what will happen when the money dries up. Will we return to our usual level of complacency and apathy? How can we best use this opportunity to really get our colleagues truly concerned and interested? We must involve them in the planning. We must study what happens when such resources are made available. We must learn from our experiences in this process. We must learn from those who actually become involved in such activities anywhere in the world. We must study what happened and must share our experiences.

The medical literature is not replete with studies of the impact of disasters on hospitals and how and why things occurred or did not occur. If we train persons in Disaster Medicine, we must study what becomes of them. How do they ply their trade? And, we must publish what we find. As disasters continue to increase in frequency and severity, we must help dissipate the apathy. We must turn disinterest into interest. And we need help as to how we can do this.

I urge each of us to go find the disaster plan for our hospital. Examine it with the perspectives you take from reading these four papers. Talk about them with your colleagues who are not involved with Disaster Medicine. Continue to ask: "What if?" Get them to personalize what will happen to them when it does occur. Ask them about the specifics of the disaster plan that impacts upon them. Be prepared to be rebuffed. But, when some tactic works, let us all know what you did. Write a letter to me and hence to all of us. We need to know how to do this thing.

Hospitals are the flagships of the health-care system, no matter where you are. Hospitals set the example for the rest of health care. If the hospitals are not prepared, how can we expect any other part of the health-care system to be prepared. We must be prepared, for surely, once it is said, "It will not happen to us," it surely will.

The cat is in the parlor, the dog is in the lake;

The cow is in the hammock-what difference does it make?

Unknown

\section{Bibliography}

Drory M, Posen J, Doron V, Ginzburg K, Lederman B: An Israeli Model of a Hospital Emergency Information Center; Prehospital and Disaster Medicine: $1999 ; 14(1): 13-16$.

Heyman SN, Eldad A, Wiener M: Airborne field hospital in disaster area: Lessons from Armenia (1988) and Rwanda (1994). Prehospital and Disaster Medicine 1998;13(1):21-28.

Levi L, Bregman D, Geva H, Revach M: Hospital disaster management simulation system. Prebospital and Disaster Medicine 1998;13(1):29-34.

Gofrit ON, Leibovici D, Shemer J, Henig A, Shapira SC: The efficacy of integrating "Smart Simulated Casualties" in hospital disaster drills. Prebospital and Disaster Medicine 1997;12(2):97-101.

Villarreal MS: Quality management tool for mass casualty emergency responses and disasters. Prehospital and Disaster Medicine 1997;12(3): $200-209$.
Levi L, Bregman D, Geva H, Revah M: Does the number of beds reflect the surgical capability of hospitals in wartime and disaster? The use of a simulation technique at a national level. Prebospital and Disaster Medicine 1997;12(4):300-304.

Londorf D: Hospital application of the incident management system. Prehospital and Disaster Medicine 1995;10(3):184-188.

Kai T, Ukai T, Ohta M, Pretto E: Hospital disaster preparedness in Osaka, Japan. Prehospital and Disaster Medicine 1994;9(1):29-34.

Noji E: Hospital disaster preparedness in Osaka, Japan. Prehospital and Disaster Medicine 1994;9(2):94-95. Editorial.

Martchenke J, Pointer JE: Hospital disaster operations during the 1989 Loma Prieta Earthquake. Prehospital and Disaster Medicine 1994;9(3):146-153.

Smith JS Jr: Hospital disaster and evacuation planning. Prehospital and Disaster Medicine 1990;5(4):357-362. 